\title{
O PROBLEMA DA DEFINIÇÃO DO DIREITO
}

\author{
Ulysses de Mello e Silva \\ Professor da Faculdade de Direito da \\ Universidade do Paraná.
}

Constitui tese de aceitação unânime ser a ciência filha da "necessidade". Ensina-nos a Economia que as necessidades, em número ilimitado, constituem a razão do progresso humano. E os fatos estão a confirmá-la.

Paul Descamps, em obra intitulada "Sociologia Experimental", conta-nos como as necessidades vêm, através dos tempos, construindo o edifício do saber humano. Nessa obra, mostra-nos a maneira pela qual surgiu, entre os egípcios, a geometria. Depois do período de unificação daquele país, no início dos tempos históricos, houve necessidade, em virtude do govêrno que ali se estabelecera, fortemente unificado, de se aumentar a produção, e, consequentemente, por parte da autoridade governamental, de um sistema que melhor arrecadasse os impostos. E, para o referido aumento os egípcios tiveram necessidade de levar as águas do Nilo, por um processo de irrigação, a grandes extensões, de tal sorte que a produção aumentasse pelo aumento das áreas cultivadas. No princípio, foi trabalho empírico, sem plano, e sem conhecimento teórico daquela tarefa que

Aula inaugural proferida no dia 10 de março de 1954, seoundo notas taquigráficas. 
realizavam. Acontece, porém, que, com o correr dos tempos, os egípcios não só chegaram ao conhecimento das várias figuras que formavam os canais, como, também, da relação que existia entre as figuras daquelas áreas cultivadas e a produção. Conheceram, desta forma, o triângulo, o quadrilátero, as figuras geométricas de um modo geral, e chegaram, mesmo, ao conhecimento das relações existentes entre a circunferência e o seu diâmetro para cálculo da superfície do círculo.

Informa-nos, ainda, o referido autor, que idêntico processo de formação teve a ciência Astronômica, a Hidráulica, a Política e também a Sociologia.

A Sociologia nasceu, na Europa, no período atormentado da "Revolução Francesa", em virtude de problemas econômicos, sociais e políticos, que estavam a exigir das pessoas mais capacitadas uma solução.

Levados por êste pensamento, entendemos que, nos dias atuais, há um problema fundamental que se apresenta diante de todos de modo enérgico, o denominado social, e que também está a exigir uma solução.

Efetivamente o problema atual é o da Justiça. Dizemos, "Justiça", realização de um valor supremo, tal como foi compreendida por Aristóteles, na "Ética a Nicômaco". Explica o filósofo que a Justiça deve ser compreendida como virtude por excelência, síntese de todos os valores, valor completo, acabado, causa e fim dos demais valores.

Êsse é o sentido do problema atual, problema de justiça, compreendendo-se, aí, Justiça como valor supremo, em cujo seio tôdas as virtudes se encontram. Mas, como buscá-la? Sòmente por um caminho - o do Direito. Qual o instrumento capaz de realizá-lo? - o Direito. A humanidade presente vive a dor dos que têm sêde e fome de Justiça. Ao Direito, Prometeu do homem moderno, cabe fartá-la; cabe-lhe, mais uma vez, salvar a humanidade da destruição, em nome do amor, como o fêz outrora a divindade grega.

Mas, que é o Direito? Quais as dificuldades que preliminarmente teremos de afastar para obtermos sua definição? 
"O problema da definição do Direito" será o tema sôbre o qual, modesta, mais sinceramente, pretendemos dissertar.

Encontraremos nesta tarefa duas ordens de dificuldades: inerentes a conceito de ciência, onde incluiremos as epistemológicas, e outras próprias da natureza do Direito.

No sentido de solucionar as primeiras, preliminarmente, faremos a distinção entre conhecimento vulgar e científico. 0 primeiro a distinguí-los foi Platão. Ao vulgar, chamou doxa e, ao científico, episteme, e introduziu critérios capazes de distinguir um grupo do outro. Doxa seria apenas conhecimento comum das coisas, dos entes. Episteme seria o conhecimento encontrado depois de trabalho reflexivo, sujeito a leis e princípios, subordinado a método certo e com objeto também certo ou específico.

Mas, na enumeração das condições do conhecimento, encontraremos os primeiros elementos que irão dificultar a conceituação de ciência, porque ao surgirem as leis, os princípios, os objetos e os métodos, iremos deparar dificuldades próprias e inerentes à natureza de tais elementos.

Vejamos: As leis, por sua natureza, constituem matéria controvertida por excelência. Filósofos e cientistas pretendem que o conhecimento científico deve estar subordinado à chamada lei da causalidade a qual permite, sòmente ela, "prever para prover". Parece-nos que as distinções introduzidas entre as leis reguladoras dos fenômenos naturais e as reguladoras dos fenômenos sociais têm propósitos diferentes. Mas se admitirmos que o mundo está subordinado exclusivamente à lei da causalidade, surgirá, como primeira dificuldade, que talvez não possa ser resolvida, o fato de se admitir, também, que estas mesmas leis estão subordinadas a princípios metafísicos que constituem os seus fundamentos. Estes princípios indicados por Desidério Papp em obra intitulada "A Natureza das Leis Científicas", são em número de três: $1^{\circ}$ ) crença no mundo exterior; $2 .^{\circ}$ ) crença que êste mundo é regido por leis; $3 .^{\circ}$ ) crença que estas leis são racionais, isto é, podem ser conhecidas pela razão humana. 
Só depois de admitidas tais bases metafísicas, sôbre as mesmas construiremos o mundo científico.

Outras dificuldades são próprias do objeto. Existe a pretensão de alguns filósofos e cientistas de realizar velha aspiração humana reduzindo à unidade a multiplicidade dos objetos. Contudo somos obrigados a admitir, em face das realidades, que os objetos não podem ser agrupados, ou reunidos sob denominador comum. Em investigação epistemológica somos obrigados a admitir pelo menos quatro objetos de natureza distinta. São êles:

Os ideais, matéria própria da ciência Matemática e Lógica; os reais, das ciências Físicas, Naturais;

os culturais, das ciências Sociais; e, por último, temos os metafísicos, da Metafísica.

Êstes objetos não se confundem e não podem ser estudados pelos mesmos métodos, nem podem estar sujeitos às mesmas leis. Assim sendo, poderíamos acrescentar que os objetos próprios do campo da Matemática efetivamente não existem na realidade, são ideais. Os princípios da Lógica são criações do raciocínio humano, uma garantia de validade dêsses mesmos raciocínios.

Os reais, próprios das ciências físicas ou naturais, existem no mundo que nos cerca, mas, por natureza, são completamente alheios aos valores. As chamadas ciências reais pedem o método indutivo, e têm por objeto os fenômenos físicos ou naturais, e êstes, como lei fundamental, o princípio da Causalidade e esta, como suporte lógico, a "explicação". As ciências culturais exigem outro método o empírico-dialético, porque o objeto cultural é valioso; seu suporte lógico é a "compreensão", que consiste numa tomada de posição pelo sujeito em face dos valores sociais. Os valores nos situam na vida e, ao aproveitá-los, pretendemos compreendê-los. A lei que os regula, não é a da Causalidade, mas, sim a da Finalidade.

Alcançar um único ponto em que todos os indivíduos se coloquem dentro de um determinado ângulo de visão, e aceitem as mesmas verdades, seria o ideal. Se as leis permanecem cons- 
tantes dentro dos sistemas científicos, isto não quer dizer que a natureza destas mesmas leis nos permita agrupá-las sob denominador único. Os princípios da Lógica, os axiomas da Matemática, a causalidade física, a finalidade social não têm características comuns que nos possibilitem unificá-las, conforme pretendem, de há muito, os filósofos.

Mas, se já não fôssem inúmeras as dificuldades decorrentes dêstes princípios enunciados, ainda outras mais surgem, que dizem respeito às possibilidades, origem e essência do conhecimento.

Há possibilidade de conhecer? Parece que as respostas são de modo categórico, Sim e Não, dois extremos, o dogmático e o cético, dentro dos quais gravita o pensamento humano.

Para o dogmático não existe o problema do conhecimento, o que não acontece ao cético. Êste toma posições tais como do ceticismo subjetivo, objetivo e relativista. Mas, entre os dois sistemas, nada poderemos decidir, porque a luta se estende da mais remota antiguidade até os nossos dias.

No que diz respeito à origem do conhecimento, problema mais sério se levanta diante de nós: qual seria ela?

As atitudes humanas se estruturam em bases racionais, empíricas, criticistas, ou ainda, assumem por vezes atitudes negativistas, como a dos céticos por excelência.

Ao racionalismo cabe um lugar de evidência, porque, sob êste título, reunem-se as figuras mais expressivas do saber humano. Vê na razão a fonte de todo conhecimento; é o têrmo debaixo do qual funcionam "escolas", "doutrinas", por vêzes completamente afastadas, umas das outras.

A primeira manifestação sistemática do racionalismo, dentro do mundo grego, é o Metafísico de Platão. Criou êle o "munfunção de tais criações o mundo. Em seguida, dentro do plano racionalista de explicação dos homens e do mundo, encontraremos o racionalismo Teológico de Santo Agostinho, que, partindo de idéias neo-platônicas, atribui a Deus o papel que, nos primeiros tempos, na teoria platônica, cabe às idéias. 
No Renascimento, quando os homens se revoltaram contra a autoridade religiosa, vemos o racionalismo adquirir novos fundamentos. Hobbes, Grotius, Puffendorf, Descartes, Spinoza, dão ao racionalismo a forma Imanente, isto é, na própria razão está a razão fundamental de ser ela a fonte do conhecimento.

Modernamente, o Racionalismo assume um novo aspecto, já não é mais imanente, nem predominantemente teológico, e, alguns filósofos vão fundamentá-lo em bases lógicas e, por isto, é denominado Lógico.

Inúmeras escolas jurídicas prendem-se a êste quadro geral do racionalismo e poderiam ser enfeixadas sob um único título, de "Escolas do Direito Racional". Mas, uma vez que há um processo histórico de base jusnaturalista, simultâneo ao racionalismo, denominaremos de "Escola do Direito Natural" o período de Platão até a Revolução Francesa, a qual, nos seus princípios básicos, tem origem nessa Escola.

Inicialmente, na Inglaterra e depois na Alemanha, há um movimento de reação aos propósitos imperialistas Napoleônicos, que culmina no romantismo e despertar das nacionalidades e que, no campo do Direito, constituirá a Escola Histórica a qual é estruturada sôbre bases irracionais mas admite o Direito Natural.

Apesar do esfôrço extraordinário realizado pelos materialistas no século XIX, a idéia do Direito Natural renasceu nos dias atuais sob o nome de Teoria da Instituição.

Se o Racionalismo agrupa nomes ilustres, o empirismo, expressão diametralmente oposta, que faz do espírito táboa rasa, onde a experiência vai escrever, teve nomes representativos no campo da filosofia, tais como Bacon, Locke e Hume. 0 empirismo, no campo jurídico, reveste-se de várias formas, tais como a positivista, a materialista-histórica, a utilitarista-pragmática e a chamada Escola do Direito Comparado.

Ora, se o positivismo, no momento atual, não possui a mesma importância de outrora, nem por isto nos é dado ignorar o extraordinário papel por êle desempenhado, bem como o do materialismo-histórico, o do utilitarismo-pragmático, como doutri- 
nas adotadas presentemente pelos russos, anglo-saxônicos, expressões políticas das mais poderosas do mundo moderno.

Como terceira atitude explicativa da origem do conhecimento, temos o criticismo. KANT tentou conciliar empiristas e racionalistas. Diz não ter feito filosofia, e efetivamente, não o fez: é o autor de um método - o crítico. Deu à sensibilidade e ao entendimento os lugares que lhes competia ocupar na teoria do conhecimento. Houve, antes de KANT, outros autores que trataram dos mesmos problemas, mas êle é o verdadeiro fundador da Epistemologia ou Teoria do Conhecimento. Em obra magistral "A crítica da Razão Pura" esgotou, a seu modo, o conhecimento do mundo da natureza, isto é, do mundo do "ser", e, na "Crítica da Razão Prática", fundamentou o princípio da liberdade, que iria constituir o pressuposto das ciências normativas, isto é, do mundo do "dever ser", liberdade sem a qual o homem não poderia ser responsável. $\mathrm{E}$, não tendo possibilidades de realizar obra semelhante à "A Crítica da Razão Pura", êsse problema foi por êle simplesmente esboçado.

Com bases em KANT, ligadas à Escola do Direito Racional, e surgidas de frutos consequentes dos trabalhos criticistas, atualmente, há escolas notáveis, como a Escola de Marburgo e a de Baden. A Escola de Marburgo, nas letras jurídicas, tem à sua frente Rodolf Stammler, restaurador, na atualidade, da Filosofia do Direito, e a Escola de Baden, Gustav Radbruch, criador da axiologia Jurídica.

Se estas escolas estão representadas por expressões máximas, há, também, no campo do Direito, os seus negadores, literatos, juristas, tais como Petrarca, Erasmo, Rabelais, Montaigne, Pascal, que foram céticos quanto à falta de valor da jurisprudência como ciência. Mas, a expressão de maior valor nesta posição é a de Júlio von Kirchmann.

Kirchmann viveu no século XIX, na Alemanha, publicou a obra "A Falta de Valor da Jurisprudência como Ciência", negou a possibilidade da ciência jurídica e buscou em Aristóteles o argumento principal para tal negação. Segundo o Estagerita, só é possível a ciência quando algo permanece constante nos fenômenos. 
A Kirchmann uniram-se ilustres pensadores e, em 1870, a tese está plenamente aceita pela Alemanha, que pretendia a sua unificação. Era o momento propício porque o povo alemão aceitava, com entusiasmo, a teoria concretizadora dos seus ideais.

Ditas estas palavras, tomaremos as três correntes principais do pensamento filosófico moderno, a fim de esclarecer, dentro de cada uma delas, o problema da definição do Direito.

A primeira será a formulada por Rodolf Stammler, pertencente, dissemos, a neo-criticismo. Stammler ocupa, nos dias atuais, uma posição de grande relêvo nas letras jurídicas, por motivos políticos e ideológicos. Nascido no século passado, vivendo aproximadamente até 1938, não pôde concluir tôda a sua obra. Dada a sua formação filosófica, não trata do problema das origens do Direito, mas, sim, apresenta o Direito simplesmente no seu aspecto lógico. Não aceita, nas suas investigações, - método indutivo. A indução é própria das ciências da realidade, mas nunca das normativas. 0 método para a investigação do normativo é o crítico, uma vez que o homem possui vontade e esta vontade é capaz de realizar um fim, um valor. Devemos compreender a vontade como uma atitude de consciência. Mas, no mundo das vontades, são inúmeras as relações que ocorrem.

Essas vontades podem apresentar-se-nos isoladas ou vinculadas a outras. Quando isoladas, Stammler diz que constituem o objeto da Moral. Porque a Moral é justamente a disciplina que considera a vontade o homem em si e por si. Mas, tôda vez que a vontade humana entra em relação com outras, temos outras disciplinas: o Direito e as Normas Convencionais. Mas, acontece que, para distinguir a norma jurídica, Stammler diz mais: que as vontades, quando se enlaçam em um todo, e em que cada uma das vontades constitui um meio para a realização do fim que as outras têm em vista alcançar, êste enlace, esta nova vontade, síntese das vontades individuais integrantes, chamar-se-á Direito. 
Êsse vínculo, assim formado, se torna autárquico, donde nasce o conceito do Direito como "simples vontade autárquica e inviolável".

É, efetivamente, uma concepção formalística do Direito. Êste, como simples forma, como categoria transcedental de matéria empírica, variável. 0 empírico e variável é o econômico.

Nas relações entre o Direito e a Economia é que Stammler vai encontrar motivo de combate às idéias marxistas. Como Marx, usa a dialética de Hegel, porém na forma original, condicionando o fenômeno econômico aos pressupostos jurídicos. Isto quer dizer que o econômico, ao nascer, já está devidamente pautado pelo processo jurídico. 0 Direito deixa de ser uma superestrutura, como pretendia Engels, para ser o condicionante do econômico.

É nessa luta contra o materialismo-histórico que Stammler vai adquirir a sua maior fama. Além do conceito, admite a idéia do Direito que tem em vista um ideal de Justiça, para uma comunidade livre, comunidade que êle imagina como aquela onde os homens se respeitam e onde a solidariedade constitui $o$ motivo permanente de vida.

O positivismo, ao pretender definir o Direito, procurou, na multiplicidade dos fenômenos jurídicos, algo que permanecesse constante. Se, dentro dela, houver algo que permaneça constante, êste é o que constitui a nota caracterizadora do Direito. 0 que há de constante na multiplicidade do Direito é a Coação. Em face dessa atitude é que sofrem os positivistas acerbas críticas dos neo-criticistas. Nem sempre a afirmativa de que a coação é caracterizadora do Direito constitui uma atitude positivista, como no caso de Stahl, em obra intitulada "Direito e Doutrina do Direito", onde o autor diz que "o Direito é ordenação, norma realizada constantemente e que se exterioriza pela coação física". E Stahl não pode ser classificado de positivista.

Ihering, no livro "O Fim do Direito", diz-nos que "o Direito é a política da fôrça”, "é o conjunto de normas pelas quais o Estado exerce a coação". Afirma, em decorrência dessa dou- 
trina, que há duas espécies de coações: a física e a psíquica. Nem por isso podemos dizer que Ihering seja positivista.

Aquêle que mais contribuiu para a introdução da coação como caracterizadora do Direito foi Kant. Diz que se o Direito é liberdade, a coação é resistência oposta às restrições ao exercício dessa liberdade. Pretendeu reconhecer na estrutura do Direito a nota que o distinguiria das outras disciplinas sociais.

Mas, a verdade é que foram os neo-positivistas da Escola Sociológica Francesa os que fizeram da coação a característica, não só do Direito, mas, também, do fato social. Para êles, a coação organizada ou difusa é a base do social. E, em seguida, estabelecem a distinção entre o Direito e as outras disciplinas, afirmando ser aquêle o único que possui a coação organizada.

Kelsen diz, em livro intitulado "Altos Problemas", que o Direito é um conjunto de normas reguladoras da coação. Mas, sendo criticista, não o fundamentou nem na liberdade, nem na vontade e sim na imputabilidade.

0 insígne jurista pode ser enquadrado no rol dos positivistas, pelo método que adotou, e por sua filiação filosófica, nas escolas de Marburgo e de Baden, tendo-se mais tarde libertado de ambas, fundando a Escola de Viena.

Como criticista, admite a norma fundamental, que é um suposto lógico para a explicação do Direito, e afasta das suas investigações todos os valores que não podem constituir objeto próprio da ciência jurídica.

Identifica o Direito e o Estado e nega a possibilidade da divisão do Direito em subjetivo e objetivo. 0 subjetivo e o objetivo constituem perspectivas de ângulos em que se podem colocar os observadores. Negando, ainda, a divisão consagrada, desde a época dos romanos, do Direito em Público e Privado, diz que essa, inicialmente, atendia apenas aos interêsses dos imperadores romanos e, depois, às monarquias européias, que se constituiam no início da Idade Moderna. Efetivamente, todo Direito é público. Por último, defende a idéia da supremacia do Direito Público Internacional. 
Como terceira "posição", encontramos a corrente Fenomenológica que abandona os processos racionais da dedução e da indução para conhecimento da realidade jurídica, e vai buscar, num processo irracional, na intuição, o caminho pelo qual o espírito se remonta à fonte das essências. Estuda o Direito como objeto social e como objeto solitário. No primeiro, como Direito positivo, e, no segundo, como norma.

A corrente Fenomenológica diz que em todo Direito há, necessàriamente, phiraiidade de sujeitos, no mínimo três: o legiferador; o titular das faculdades, o sujeito ativo; e o das obrigações, o sujeito passivo. Ainca mais, o Direito tem como objeto de sua investigação o comportamento humano como "dever ser" \& não como "ser". Procurando adaptar o homem às condições sociais, o Direito deixa de ser fenômeno de adaptação para ser fenômeno adaptante. Como atividade consciente, - Direito, obrigatòriamente, tem em vista a realização de um valor, a Justiça.

Donde, como objeto coletivo, "o Direito é sistema bilateral, retribuidor de disposições postas pelo homem para regular o comportamento social do grupo, e como meio de realizar os valores da comunidade".

Chegados a êste ponto, temos de observar o seguinte: são três filosofias, três posições, três atitudes, que não podem ser conciliadas. $\mathrm{E}$ voltaríamos, assim, ao ponto inicial, ao marco zero, de onde partimos.

Ora, se esta luta se vem realizando através dos tempos, e se variam tanto as opiniões a respeito dêste tema, parece que haverá tantas concepções, tantas definições, quantas forem as filosofias que constituam o seu fundamento, e tantas quantas forem as filosofias que constituam formas de vida do homem. Porque a Filosofia é, efetivamente, uma forma de vida. Vida humana é existir, e existir, segundo o filósofo Heidgger, "é existir com, é ser com outro que está neste mundo, é viver como sendo êle". É, como diz o filósofo, a existência dotada desta cu- 
riosa dimensão que é a existência de todos. Porém, os outros não podem, todavia, converter-nos em objeto seu. Se a existência tem como suposto a liberdade, tem, como consequência, a solidariedade humana, fôrça socializadora por excelência.

Cícero, sôbre o tema da maior união entre os homens, assim se expressava:

"De tôdas as fontes do dever, a mais fecunda é a que mantém a sociedade humana e serve de fundamento à união de um homem com os outros homens. Há que se distinguir nela, primeiro, a Justiça, onde a virtude brilha com todo o seu esplendor, que é a qualidade por excelência do homem de bem; depois, a Beneficência, irmã da Justiça, e que também se pode chamar de Bondade ou Generosidade. É, como diziam os estóicos: tudo que a terra produz é criado para o uso do homem e o homem mesmo para os seus semelhantes; como a nossa lei é ajudar-nos mùtuamente, devemos ser fiéis às inspirações da Natureza, pôr em comum tôdas as nossas vantagens, mediante a troca recíproca de bons ofícios, dando e recebendo alternativamente, empregando o nosso espírito, nosso trabalho, nossos recursos em apertar os laços que unem os nomens uns aos outros, em sociedade".

A fôrça do amor e da liberdade deverão levar o homem à conquista suprema da afirmação da sua existência no mundo dos seus semelhantes.

Êste é o ideal norteador de nossa preleção, no sentido de um mundo melhor.

$\mathrm{E}$, se de alguma forma, despertarmos o ideal nos corações, no sentido da sólução dos problemas humanos, teremos atingido o nosso propósito, porque, como diz Scheller: "Todo saber é, em definitivo, de Deus e para Deus". 